\title{
Smoking Habits in Men and Women with Different Perceptions of Social Well-Being: Findings of A Large Population-Based Study
}

\author{
Hasti Masihay-Akbar \\ Research Institute for Endocrine Sciences, \\ Fahimeh Mehrabi \\ Research Institute for Endocrine Sciences \\ Neda Mardi \\ Research Institute for Endocrine Sciences \\ Parisa Amiri ( $\square$ amiri@endocrine.ac.ir) \\ Research Institute for Endocrine Sciences https://orcid.org/0000-0002-3198-4941 \\ Leila Cheraghi \\ Research Institute for Endocrine Sciences \\ Hassan Eini-Zinab \\ Department of Community Nutrition, School of Nutrition, Shahid Beheshti University \\ Fereidoun Azizi \\ Research Institute for Endocrine Sciences
}

\section{Research}

Keywords: Social well-being, Tobacco, Cigarette, Hookah

Posted Date: June 29th, 2021

DOI: https://doi.org/10.21203/rs.3.rs-633459/v1

License: @ (i) This work is licensed under a Creative Commons Attribution 4.0 International License. Read Full License 


\section{Abstract \\ Background}

This study aimed to investigate cigarette and hookah smoking in a population of Eastern-Mediterranean adults in relation to their perceived social well-being (social integration, coherence, acceptance, contribution, and actualization).

\section{Methods}

Data of 2592 adults who participated in the 6th phase (2014-2016) of the Tehran Lipid and Glucose Study (TLGS) was used. After excluding those with missing data $(n=235), 2357$ remained for the sex-specific logistic regression to investigate the association between social well-being and current smoking (cigarette and hookah). The final model (model 3) was adjusted for age, marital status, education, occupation, physical activity, and chronic disease history.

\section{Results}

Participants' mean age was $46 \pm 14$ years (45\% men). Compared to cigarette and hookah smokers, the mean scores of social well-being and all its dimensions were higher in non-smokers. While in men, cigarette smoking was significantly related to social well-being and all its dimensions, only women with higher social well-being (OR:0.97, Cl:0.95-0.99, P:0.001), social integration (OR:0.93, Cl:0.87-0.99, P:0.019), and coherence (OR:0.92, $\mathrm{Cl}: 0.87-0.98, \mathrm{P}: 0.013)$, were further at risk of cigarette smoking. Unlike men, whose hookah smoking was not at all related to their social wellbeing, women's hookah consumption was associated with social well-being (OR: 0.97, Cl:0.95-0.99, P:0.002), social integration and acceptance; one unit increase in the mean scores of social integration and acceptance in women reduced the risk of hookah use by $8 \%$.

\section{Conclusion}

Social well-being and tobacco smoking are related, and evident sex differences in this relationship should not be ignored in future tobacco control efforts.

\section{Introduction}

Tobacco smoking is a worldwide leading cause of physical and psychological disorders and premature death (1). According to the latest reports, tobacco kills more than 8 million people each year. Ranked as second in 2015, smoking-attributed Disability-Adjusted Life Years (DALYs) were 148.6 million worldwide (2). National studies in Iran reported $25.2 \%$ and $4.0 \%$ of current tobacco smoking (including cigarettes and hookah) in men and women, respectively (3). Over recent years, despite the declining trend of current cigarette smoking, the cigarette intensity has increased in smokers, and the prevalence of hookah use had a constant trend in the adult population (4); therefore, smoking still remains a public health issue in the country.

Identifying factors associated with tobacco smoking may help ease its harms at both individual and community levels. In addition to welldocumented physical and mental aspects of this matter (5-7), investigating the role of social well-being (8) is needed in this regard. To date, many efforts have been made to understand and explain the concept of social well-being (9). Starting from 1925, the hedonic theory of well-being was gradually formed, relying on the study of people's feelings about their daily lives (10). Subsequently, the eudaimonic theory of well-being emphasized the outcome of positive goal pursuits. This model is constructed based on the assumption that individuals attempt to understand their unique talents to have the best function (11). Studying well-being through a socio-sensitive lens, Keyes developed the eudaimonic theory and showed the extent to which individuals overcome social challenges and function well in society (9). He introduced a five-component model of social well-being: social integration, social contribution, social coherence, social actualization, and social acceptance (12). Existing data showed the predicting role of social acceptance and pressures and supportive social norms in individuals' tobacco smoking habits (13). Regardless of sex, cigarette and hookah smoking have been associated with social isolation (14), social norms (15), and integration to family, friends, or church, especially in youth (16). In addition to mentioned dimensions of social well-being, some studies have focused on the social indicators, including deprivation of education (17-19), unemployment (19-21), low income (22, 23), and living in deprived residential areas (15, 24). However, social well-being -as a comprehensive concept- rarely has been studied in relation to smoking.

The importance of sex differences has become more predominant in different cultural contexts. Valuing male cigarette smoking in Eastern-Asian communities (25) or considering hookah smoking in Arab countries as a common traditional entertainment for men are examples of those societies where men could gain higher social acceptance with tobacco smoking $(26,27)$. On the other hand, women's cigarette smoking is taboo in Eastern-Mediterranean cultures; therefore, lack of embarrassment, supportive social norms, and existing traditional roots could drive women to 
hookah rather than cigarette smoking (28). Recently a systematic review revealed gaining social acceptance from peers as a strong motivator for women to consume hookah (29). However, these tobacco-related sex disparities still need further in-depth investigations in different cultures.

To the best of our knowledge, despite many efforts in this regard, social well-being and its dimensions have not been studied as a comprehensive concept in relation to tobacco smoking. This study is conducted through Keyes's questionnaire, which is developed based on a comprehensive social well-being theory. Given the above-mentioned scientific gaps and the need for a deeper sex-specific study of this issue, we aimed to investigate the association between perceived social well-being and smoking habits (cigarette and hookah) among a large population of Iranian men and women.

\section{Methods}

\section{Study population}

This study is conducted in the Tehran Lipid and Glucose Study (TLGS) framework, an ongoing prospective cohort study aimed to investigate noncommunicable diseases and their risk factors among residents of district 13 of Tehran, capital of Iran. In brief, the TLGS started with a crosssectional phase in 1999 and continued with every-three-year measurements afterward. The reason for selecting district 13 was the generalizability of its residents' socio-demographic status to the whole population of Tehran. Three of 20 health centers were chosen, and 15,005 individuals (aged $\geq$ three years) were selected via a multistage cluster random sampling technique.

The data of 2592 adults (age > 19 years) who participated in the 6th phase of the TLGS (2014-2016) was used in the current study. After excluding those with missing data $(n=235), 2357$ remained for the analysis. This study was approved by the ethical committee of the research institute for endocrine (RIES), and written informed consent was obtained from all participants.

\section{Measurements}

Using standard questionnaires, trained interviewers obtained essential information regarding socio-demographic characteristics (age, education, occupation, marital status), smoking, physical activity, chronic disorders, and social well-being. The education level was categorized based on having an academic education. Participants with or without a job were classified as "employed" and "unemployed". Individuals who were single, widow/widower, or divorced at the time of the interview were classified as currently single. Physical activity was assessed using a Persian translated and validated version of the Modifiable Activity Questionnaire (MAQ) (30). In this regard, the metabolic equivalent task (MET) of the particular act (sport, job, and travel) during one week was multiplied by the weight. The sum of all actions is considered total energy expenditure in adults. Subsequently, it was categorized into groups of low (<600), moderate (600-3000), and high ( $\geq 3000)$ physical activity. A positive history for each of diabetes mellitus (DM), chronic kidney disease (CKD), cardiovascular disease (CVD), or cancer was taken into account to chronic disease history.

In terms of smoking habits, a current smoker (cigarette or hookah) was defined as a person who smoked cigarettes/hookah daily or occasionally. Those who did not report any tobacco use were considered non-smokers.

Social well-being was assessed using the short-form of Keyes social well-being questionnaire (12), which has been already validated in the Iranian population (31). It includes 15 items and evaluates social well-being in five dimensions, each measured with three questions. Questions were on a 7-point agreement scale ( 1 = strongly agree to 7 = strongly disagree). The social well-being dimensions consist of social integration, acceptance, coherence, contribution, and actualization.

Social integration is the feeling of belonging to the society and the sense of supporting and sharing the community. Social acceptance represents to what extent the community and its people accept the individuals with all the defects, positive and negative aspects. Social coherence represents to what extent an individual thinks the community is understandable, reasonable, and predictable. Social contribution is a feeling of being important to society and having something positive to offer. Social actualization believes that society and individuals have the potential for growth and help each other be positive (12).

\section{Statistical analysis}

At first, data was split by sex, and then frequencies and mean ( \pm standard deviation) were represented for qualitative and quantitative variables, respectively. To compare qualitative and quantitative variables, a chi-square test was used among the smoking habits groups. The covariance test was done comparing the mean of social well-being and subscales among smoking habits for men and women, respectively. Finally, logistic regression was done to estimate odds ratios (ORs with 95\% confidence), and the association was determined in three steps. First result adjusted for age, marital status, educational level, and occupational level (model 1). Second physical activity was added to eliminate the effects of these potentially confounding variables (model 2). Finally, in the third step, the chronic disorder was included in the analysis (model 3) to examine whether this covariate affected the association. Results were reported according to gender. Analyses were done by SPSS 20 , and a p-value of 0.05 was considered significant. 


\section{Results}

Table 1 displays the characteristics of the study participants. The mean age of participants was $46 \pm 14$ years ( $45 \%$ men). In all three non-smokers, cigarette smokers, and hookah smokers groups, the majority were married (75.1\% men and 73.1 women) and had a high school degree or less (62.5\% men and $66.3 \%$ women). Most men were employed (72\%), while most $80 \%$ of women were unemployed. $63 \%$ of cigarette smoker men and $73.5 \%$ of non-smoker women had moderate or high physical activity. $29.7 \%$ and $28.7 \%$ of cigarette and hookah smoker men, and $36.8 \%$ and $27.1 \%$ of cigarette and hookah smokers women at least had a chronic disease.

Table 1

Sex-specific characteristics of study participants in smoking groups ( $N=2357)$.

\begin{tabular}{|c|c|c|c|c|c|c|c|c|c|c|}
\hline & \multicolumn{5}{|c|}{ Men $(n=1068)$} & \multicolumn{5}{|c|}{ Women $(n=1289)$} \\
\hline & Total & $\begin{array}{l}\text { Nonsmoker } \\
(n=672)\end{array}$ & $\begin{array}{l}\text { Cigarette } \\
\text { smoker } \\
(n=246)\end{array}$ & $\begin{array}{l}\text { Hookah } \\
\text { smoker } \\
(n=150)\end{array}$ & $\begin{array}{l}\mathrm{P} \text { - } \\
\text { value }\end{array}$ & Total & $\begin{array}{l}\text { Nonsmoker } \\
(n=1147)\end{array}$ & $\begin{array}{l}\text { Cigarette } \\
\text { Smoker } \\
(n=57)\end{array}$ & $\begin{array}{l}\text { Hookah } \\
\text { Smoker } \\
(n=85)\end{array}$ & $\begin{array}{l}P \text { - } \\
\text { value }\end{array}$ \\
\hline Age(year) & $\begin{array}{l}46.7 \pm \\
15.9\end{array}$ & $50.6 \pm 16.1$ & $\begin{array}{l}41.42 \pm \\
13.3\end{array}$ & $\begin{array}{l}37.1 \pm \\
11.9\end{array}$ & $<.001$ & $46.7 \pm 14.1$ & $47.9 \pm 13.9$ & $\begin{array}{l}42.0 \pm \\
13.02\end{array}$ & $\begin{array}{l}33.7 \pm \\
10.2\end{array}$ & $\begin{array}{l}< \\
0.001\end{array}$ \\
\hline $\begin{array}{l}\text { Marital } \\
\text { status }\end{array}$ & & & & & $<.001$ & & & & & $<.001$ \\
\hline $\begin{array}{l}\text { Currently } \\
\text { single }\end{array}$ & $266(24.9)$ & 130(19.3) & $80(32.5)$ & $56(37.3)$ & & $341(26.5)$ & $282(24.6)$ & $21(36.8)$ & $38(44.7)$ & \\
\hline Married & $802(75.1)$ & $542(80.7)$ & $166(67.5)$ & $94(62.7)$ & & $948(73.5)$ & $865(75.4)$ & $36(63.2)$ & $47(55.3)$ & \\
\hline $\begin{array}{l}\text { Educational } \\
\text { level }\end{array}$ & & & & & 0.790 & & & & & 0.042 \\
\hline $\begin{array}{l}\text { High school } \\
\text { or less }\end{array}$ & $667(62.5)$ & $415(61.8)$ & $158(64.2)$ & $94(62.7)$ & & $845(66.3)$ & $773(67.4)$ & $34(59.6)$ & $47(55.3)$ & \\
\hline $\begin{array}{l}\text { Academic } \\
\text { degree }\end{array}$ & $401(37.5)$ & $257(38.2)$ & $88(35.8)$ & $56(37.3)$ & & 435(33.7) & $374(32.6)$ & $23(40.4)$ & $38(44.7)$ & \\
\hline Occupation & & & & & $\begin{array}{l}< \\
0.001\end{array}$ & & & & & $\begin{array}{l}< \\
0.001\end{array}$ \\
\hline Unemployed & $291(27.2)$ & $238(35.4)$ & $33(13.4)$ & $20(13.3)$ & & 1035(80.3) & $942(82.1)$ & $38(66.7)$ & $55(64.7)$ & \\
\hline Employed & $777(72.8)$ & $434(64.6)$ & 213(86.6) & 130(86.7) & & 254(19) & 205(17.9) & 19(33.3) & $30(35.3)$ & \\
\hline $\begin{array}{l}\text { Physical } \\
\text { activity }\end{array}$ & & & & & 0.953 & & & & & 0.737 \\
\hline Low & $404(37.8)$ & $256(38.1)$ & $91(37.0)$ & $57(38.0)$ & & $346(26.8)$ & $304(26.5)$ & 17(29.8) & $25(29.4)$ & \\
\hline $\begin{array}{l}\text { Moderate/ } \\
\text { high }\end{array}$ & $664(62.2)$ & $416(61.9)$ & $155(63.0)$ & $93(62.0)$ & & $943(73.2)$ & $843(73.5)$ & $40(70.2)$ & $60(70.6)$ & \\
\hline $\begin{array}{l}\text { Chronic } \\
\text { disorder }\end{array}$ & & & & & $<.001$ & & & & & < 0.001 \\
\hline No & $621(58.1)$ & $341(50.7)$ & $173(70.3)$ & 107(71.3) & & $695(53.9)$ & $597(52.0)$ & $36(63.2)$ & $62(72.9)$ & \\
\hline Yes & 447(41.9) & $331(49.3)$ & 73(29.7) & $43(28.7)$ & & $594(46.1)$ & $550(48.0)$ & 21(36.8) & $23(27.1)$ & \\
\hline
\end{tabular}

The mean of social well-being score and its dimensions among non-smokers and smokers groups (either cigarette smokers or hookah smokers) were presented in Fig. 1 for men and women. In total, higher means of social well-being and its dimensions were observed in the non-smokers' group rather than the smokers' group. After adjusting for age, marital status, educational level, occupational level, physical activity, and chronic disorders, the means of social well-being and its dimensions were presented in Table 2. There was a significant difference between the mean scores of smoking groups (non-smoker, cigarette, and hookah smoker) in men ( $p$-value: <0.001) and women ( $p$-value: 0.001). The means of all social well-being dimensions had a significant difference in men, while just means of social integration ( $p$-value: 0.002$)$, social coherence ( $p$-value: 0.039), and social actualization (p-value: 0.037 ) were significantly different across women smoking groups. 
Table 2

The adjusted mean scores of social well-being and its dimensions in smoking groups of men and women.

\begin{tabular}{|c|c|c|c|c|c|c|c|c|}
\hline & \multicolumn{4}{|l|}{ Men } & \multicolumn{4}{|l|}{ Women } \\
\hline & $\begin{array}{l}\text { Non- } \\
\text { smokers }\end{array}$ & $\begin{array}{l}\text { Cigarette } \\
\text { smokers }\end{array}$ & $\begin{array}{l}\text { Hookah } \\
\text { smokers }\end{array}$ & $\begin{array}{l}\mathrm{P} \text { - } \\
\text { value }\end{array}$ & $\begin{array}{l}\text { Non- } \\
\text { smokers }\end{array}$ & $\begin{array}{l}\text { Cigarette } \\
\text { smokers }\end{array}$ & $\begin{array}{l}\text { Hookah } \\
\text { smokers }\end{array}$ & $\begin{array}{l}\mathrm{P} \text { - } \\
\text { value }\end{array}$ \\
\hline Social well-being & $\begin{array}{l}69.90( \pm \\
0.62)\end{array}$ & $65.15( \pm 0.96)$ & $67.77( \pm 1.19)$ & $\begin{array}{l}< \\
0.001\end{array}$ & $\begin{array}{l}68.95( \pm \\
0.57)\end{array}$ & $63.87( \pm 1.84)$ & $64.57( \pm 1.57)$ & 0.001 \\
\hline $\begin{array}{l}\text { Social } \\
\text { integration }\end{array}$ & $\begin{array}{l}14.97( \pm \\
0.19)\end{array}$ & $14.05( \pm 0.29)$ & $14.44( \pm 0.36)$ & 0.013 & $\begin{array}{l}13.87( \pm \\
0.17)\end{array}$ & $12.50( \pm 0.56)$ & $12.50( \pm 0.47)$ & 0.002 \\
\hline $\begin{array}{l}\text { Social } \\
\text { acceptance }\end{array}$ & $\begin{array}{l}11.36( \pm \\
0.17)\end{array}$ & $10.69( \pm 0.26)$ & $10.84( \pm 0.32)$ & 0.043 & $\begin{array}{l}11.48( \pm \\
0.15)\end{array}$ & $10.81( \pm 0.48)$ & $10.71( \pm 0.41)$ & 0.097 \\
\hline Social coherence & $\begin{array}{l}14.76( \pm \\
0.19)\end{array}$ & $13.90( \pm 0.29)$ & $14.30( \pm 0.36)$ & 0.023 & $\begin{array}{l}14.78( \pm \\
0.16)\end{array}$ & $13.41(0.54)$ & $14.39( \pm 0.46)$ & 0.037 \\
\hline $\begin{array}{l}\text { Social } \\
\text { contribution }\end{array}$ & $\begin{array}{l}15.13( \pm \\
0.20)\end{array}$ & $14.09( \pm 0.32)$ & $14.81( \pm 0.40)$ & 0.011 & $\begin{array}{l}14.85( \pm \\
0.19)\end{array}$ & $14.39( \pm 0.63)$ & $14.12( \pm 0.53)$ & 0.347 \\
\hline $\begin{array}{l}\text { Social } \\
\text { actualization }\end{array}$ & $\begin{array}{l}13.67( \pm \\
0.24)\end{array}$ & $12.41( \pm 0.37)$ & $13.36( \pm 0.46)$ & 0.007 & $\begin{array}{l}13.95( \pm \\
0.20)\end{array}$ & $12.47( \pm 0.66)$ & $12.82( \pm 0.56)$ & 0.039 \\
\hline
\end{tabular}

Table 3 summarizes the logistic regression analysis results on the association between social well-being and smoking habits. The full adjusted model results indicated that a one-unit increase in social well-being scores decreases the risk of smoking cigarettes by $3 \%$ for men and women (OR: 0.97 , p-value: $<0.001$ for both sex). Results also showed that cigarette smoking is associated significantly with per scale of social well-being for men (social integration: OR: 0.95, p-value: 0.008, social acceptance: OR: 0.95, p-value: 0.018, social coherence: OR: 0.95, p-value: 0.006, social contribution: OR: 0.95, p-value: 0.003, and social actualization: OR: 0.95, p-value: 0.002). In women, the higher scores of social integration and social coherence were associated with decreased cigarette smoking risk by $7 \%$ and $8 \%$, respectively (Social integration: OR: 0.93 , p-value: 0.019 ; social coherence: OR: 0.92, p-value: 0.013 ). There was no significant association between social acceptance, social contribution, and social actualization scales with cigarette smoking in women. Results also indicated no evidence of a significant relationship between social well-being and hookah smoking in men. For women, a one-unit increase in social well-being scores decreased the risk of hookah smoking by $3 \%$ (OR: 0.97 , pvalue: 0.002). Moreover, higher social integration scores and social acceptance were associated with a decrease in the chance of hookah smoking by $8 \%$ (social integration: OR: 0.92, p-value: 0.005; social acceptance: OR: 0.092, p-value: 0.027). There was no significant relationship between social coherence, social contribution, and social actualization with hookah smoking in women. 
Table 3

Sex-specific adjusted odds ratios and 95\% confidence intervals of smoking habits for social well-being and its dimensions.

\begin{tabular}{|c|c|c|c|c|c|c|c|c|c|}
\hline & & \multicolumn{4}{|l|}{ Men } & \multicolumn{4}{|l|}{ Women } \\
\hline & & \multicolumn{2}{|c|}{ Cigarette Smoking } & \multicolumn{2}{|c|}{ Hookah Smoking } & \multicolumn{2}{|c|}{ Cigarette Smoking } & \multicolumn{2}{|c|}{ Hookah Smoking } \\
\hline & & $O R *(95 \% \mathrm{Cl})$ & $\begin{array}{l}\mathrm{p}- \\
\text { value }\end{array}$ & $\mathrm{OR} \star \star(95 \% \mathrm{Cl})$ & $\begin{array}{l}\mathrm{p}- \\
\text { value }\end{array}$ & $O R^{*}(95 \% \mathrm{Cl})$ & $\begin{array}{l}\mathrm{p}- \\
\text { value }\end{array}$ & $O R^{\star \star}(95 \% \mathrm{Cl})$ & $\begin{array}{l}\mathrm{p}- \\
\text { value }\end{array}$ \\
\hline \multirow[t]{6}{*}{$\begin{array}{l}\text { Model } \\
1\end{array}$} & Social well-being & $\begin{array}{l}0.97(0.96- \\
0.99)\end{array}$ & $\begin{array}{l}< \\
0.001\end{array}$ & $\begin{array}{l}0.99(0.97- \\
1.00)\end{array}$ & 0.109 & $\begin{array}{l}0.97(0.95- \\
0.99)\end{array}$ & 0.008 & $\begin{array}{l}0.97(0.96- \\
0.99)\end{array}$ & 0.003 \\
\hline & Social integration & $\begin{array}{l}0.95(0.91- \\
0.98)\end{array}$ & 0.005 & $\begin{array}{l}0.97(0.93- \\
1.02)\end{array}$ & 0.283 & $\begin{array}{l}0.93(0.87- \\
0.99)\end{array}$ & 0.019 & $\begin{array}{l}0.92(0.87- \\
0.98)\end{array}$ & 0.006 \\
\hline & $\begin{array}{l}\text { Social } \\
\text { acceptance }\end{array}$ & $\begin{array}{l}0.95(0.91- \\
0.99)\end{array}$ & 0.022 & $\begin{array}{l}0.96(0.91- \\
1.02)\end{array}$ & 0.176 & $\begin{array}{l}0.95(0.88- \\
1.02)\end{array}$ & 0.180 & $\begin{array}{l}0.93(0.86- \\
0.99)\end{array}$ & 0.033 \\
\hline & Social coherence & $\begin{array}{l}0.95(0.91- \\
0.98)\end{array}$ & 0.005 & $\begin{array}{l}0.96(0.92- \\
1.01)\end{array}$ & 0.177 & $\begin{array}{l}0.92(0.87- \\
0.98)\end{array}$ & 0.013 & $\begin{array}{l}0.95(0.90- \\
1.01)\end{array}$ & 0.120 \\
\hline & $\begin{array}{l}\text { Social } \\
\text { contribution }\end{array}$ & $\begin{array}{l}0.95(0.92- \\
0.98)\end{array}$ & 0.004 & $\begin{array}{l}0.98(0.94- \\
1.03)\end{array}$ & 0.409 & $\begin{array}{l}0.98(0.92- \\
1.04)\end{array}$ & 0.458 & $\begin{array}{l}0.95(0.90- \\
1.01)\end{array}$ & 0.094 \\
\hline & $\begin{array}{l}\text { Social } \\
\text { actualization }\end{array}$ & $\begin{array}{l}0.95(0.93- \\
0.98)\end{array}$ & 0.002 & $\begin{array}{l}0.99(0.95- \\
1.02)\end{array}$ & 0.506 & $0.95(0.90-1.00)$ & 0.072 & $\begin{array}{l}0.96(0.92- \\
1.01)\end{array}$ & 0.098 \\
\hline \multirow[t]{6}{*}{$\begin{array}{l}\text { Model } \\
2\end{array}$} & Social well-being & $\begin{array}{l}0.97(0.96- \\
0.99)\end{array}$ & $<.001$ & $\begin{array}{l}0.99(0.97- \\
1.00)\end{array}$ & 0.115 & $\begin{array}{l}0.97(0.95- \\
0.99)\end{array}$ & 0.008 & $\begin{array}{l}0.97(0.96- \\
0.99)\end{array}$ & 0.003 \\
\hline & Social integration & $\begin{array}{l}0.95(0.91- \\
0.98)\end{array}$ & 0.005 & $\begin{array}{l}0.97(0.93- \\
1.02)\end{array}$ & 0.292 & $\begin{array}{l}0.93(0.87- \\
0.99)\end{array}$ & 0.019 & $\begin{array}{l}0.92(0.87- \\
0.98)\end{array}$ & 0.006 \\
\hline & $\begin{array}{l}\text { Social } \\
\text { acceptance }\end{array}$ & $\begin{array}{l}0.95(0.91- \\
0.99)\end{array}$ & 0.023 & $\begin{array}{l}0.96(0.91- \\
1.01)\end{array}$ & 0.176 & $\begin{array}{l}0.95(0.88- \\
1.02)\end{array}$ & 0.179 & $\begin{array}{l}0.93(0.86- \\
0.99)\end{array}$ & 0.032 \\
\hline & Social coherence & $\begin{array}{l}0.95(0.91- \\
0.98)\end{array}$ & 0.006 & $\begin{array}{l}0.97(0.92- \\
1.01)\end{array}$ & 0.187 & $\begin{array}{l}0.92(0.87- \\
0.98)\end{array}$ & 0.013 & $\begin{array}{l}0.95(0.90- \\
1.01)\end{array}$ & 0.120 \\
\hline & $\begin{array}{l}\text { Social } \\
\text { contribution }\end{array}$ & $\begin{array}{l}0.95(0.92- \\
0.98)\end{array}$ & 0.004 & $\begin{array}{l}0.98(0.94- \\
1.03)\end{array}$ & 0.426 & $\begin{array}{l}0.98(0.92- \\
1.04)\end{array}$ & 0.463 & $\begin{array}{l}0.95(0.90- \\
1.01)\end{array}$ & 0.094 \\
\hline & $\begin{array}{l}\text { Social } \\
\text { actualization }\end{array}$ & $\begin{array}{l}0.95(0.93- \\
0.98)\end{array}$ & 0.002 & $\begin{array}{l}0.99(0.95- \\
1.02)\end{array}$ & 0.512 & $0.95(0.90-1.00)$ & 0.071 & $\begin{array}{l}0.96(0.92- \\
1.01)\end{array}$ & 0.097 \\
\hline \multirow[t]{6}{*}{$\underset{3}{\text { Model }}$} & Social well-being & $\begin{array}{l}0.97(0.96- \\
0.99)\end{array}$ & $<001$ & $\begin{array}{l}0.99(0.97- \\
1.00)\end{array}$ & 0.118 & $\begin{array}{l}0.97(0.95- \\
0.99)\end{array}$ & 0.001 & $\begin{array}{l}0.97(0.95- \\
0.99)\end{array}$ & 0.002 \\
\hline & Social integration & $\begin{array}{l}0.95(0.91- \\
0.99)\end{array}$ & 0.005 & $\begin{array}{l}0.97(0.92- \\
1.02)\end{array}$ & 0.299 & $\begin{array}{l}0.93(0.87- \\
0.99)\end{array}$ & 0.019 & $\begin{array}{l}0.92(0.87- \\
0.98)\end{array}$ & 0.005 \\
\hline & $\begin{array}{l}\text { Social } \\
\text { acceptance }\end{array}$ & $\begin{array}{l}0.95(0.91- \\
0.99)\end{array}$ & 0.018 & $\begin{array}{l}0.96(0.91- \\
1.02)\end{array}$ & 0.183 & $\begin{array}{l}0.95(0.88- \\
0.1 .0)\end{array}$ & 0.177 & $\begin{array}{l}0.92(0.86- \\
0.99)\end{array}$ & 0.027 \\
\hline & Social coherence & $\begin{array}{l}0.95(0.91- \\
0.98)\end{array}$ & 0.006 & $\begin{array}{l}0.97(0.92- \\
1.02)\end{array}$ & 0.188 & $\begin{array}{l}0.92(0.87- \\
0.98)\end{array}$ & 0.013 & $\begin{array}{l}0.95(0.90- \\
1.01)\end{array}$ & 0.126 \\
\hline & $\begin{array}{l}\text { Social } \\
\text { contribution }\end{array}$ & $\begin{array}{l}0.95(0.92- \\
0.98)\end{array}$ & 0.003 & $\begin{array}{l}0.98(0.94- \\
1.03)\end{array}$ & 0.446 & $\begin{array}{l}0.98(0.92- \\
1.04)\end{array}$ & 0.464 & $\begin{array}{l}0.95(0.90- \\
1.01)\end{array}$ & 0.089 \\
\hline & $\begin{array}{l}\text { Social } \\
\text { actualization }\end{array}$ & $\begin{array}{l}0.95(0.93- \\
0.98)\end{array}$ & 0.002 & $\begin{array}{l}0.99(0.95- \\
1.02)\end{array}$ & 0.499 & $0.95(0.90-1.00)$ & 0.072 & $\begin{array}{l}0.95(0.91- \\
1.01)\end{array}$ & 0.094 \\
\hline \multicolumn{10}{|c|}{ Model 1: adjusted for age, marital status, educational level, and occupational level. } \\
\hline \multicolumn{10}{|c|}{ Model 2: adjusted for previous variables and physical activity. } \\
\hline
\end{tabular}

\section{Discussion}

The present study examined the association of perceived social well-being and smoking habits, including cigarette and hookah consumption in a large population of adult men and women. Considering social well-being as a comprehensive concept, we assessed different dimensions of social well-being via Keyes's questionnaire. The current findings revealed sex differences in social well-being association with tobacco smoking. Our results showed a negative association between social well-being and cigarette smoking in both sexes. Whereas all social well-being dimensions were associated with cigarette smoking in men, a lower risk of women's smoking was only observed in higher social integration and coherence 
scores. In terms of hookah smoking, in women, higher scores in social well-being, social integration, and acceptance reduced the risk of hookah consumption, while in men, there was no relationship in this regard.

In terms of cigarette smoking, our results showed that higher social well-being scores reduce the risk of cigarette use in men and women, while there were sex differences in the association between cigarette smoking and social well-being dimensions. Men's smoking is related to all social well-being dimensions, whereas only women with lower social integration and coherence tend to smoke more. In the existing literature, the association has not been directly studied before. However, a number of studies focused on some social determinants of smoking, all arguing the importance of the social situation in forming smoking behaviors. Education, income, marital status, neighborhood, perceived inequality, and degree of trust and safety in a community have been considered potential determinants of smoking in previous studies (32-35). Another investigated factor is social support, which causes the formation and change of smoking behavior, especially in vulnerable populations such as pregnant women (36). Accordingly, having a sense of belonging to a community that could provide social support has a protective effect on the tendency to smoke cigarettes $(32,37)$. Gender differences are reflected in the details of the dimensions of social well-being. In line with our finding, sex and cultural interaction have been considered essential in cigarette smoking habits in previous studies. It is well-known that cigarette smoking is shameful for women in Eastern societies while being valued for men (38). Deficiency in any dimension of men's social well-being could lead them to smoke. Yet, the case for cigarette smoking is quite different in women; despite the mentioned facts, low social coherence in women could overweigh the social norms, thus leading them to smoke and driving them to take the risk of not being accepted by others.

On the subject of hookah smoking, its consumption risk in women decreased significantly with higher social well-being, integration, and acceptance. In contrast, no relationship was found with any dimensions of men's social well-being. Hookah smoking is generally considered a group activity behavior (39), yet the observed sex differences could simply be rooted in different underlying motivators in men and women. While men seek joy through hookah smoking in their gatherings, women get acceptance with this social activity (39). In this regard, a large body of evidence emphasized the impacts of women's environmental situation on their attitudes, leading to hookah smoking behavior (29). Society's view directs people's behavior, and this principle is quite evident in women's smoking in Eastern cultures, where consuming hookah is more socially acceptable for them (28). Even in some of these communities, women achieve social acceptance through hookah smoking with their friends and families $(40,41)$.

This study is one of the first attempts in a Middle-Eastern society to assess the relation of social well-being and its dimensions with smoking behaviors; it provides a further in-depth and comprehensive view of the social well-being concept introduced by Keyes in relation to tobacco use. In a culture where attitudes towards smoking are different in men and women, sex-specific analysis in a large sample of Iranian adults allows comparison. There are also some limitations in the present study. First, due to the cross-sectional nature of this study, causal interpretation is not possible. Second, because of the sensitivity of the tobacco issue, especially in women in the Middle East, their self-reported data might be subject to report bias. Third, since this study's population is limited to the urban regions, the results could not be generalized to the rural areas.

In conclusion, due to the Middle Eastern culture and different attitudes towards smoking in men and women, gender differences were observed in the relationship between smoking and social well-being. Except for hookah smoking in men, other smoking behaviors in both sexes are significantly related to social well-being. Men with higher scores in all dimensions of social well-being, including integration, coherence, cohesion, acceptance, actualization, are less likely to smoke. However, in women, higher scores of social integration reduce the risk of cigarettes and hookah smoking, while social coherence and acceptance were related to cigarette and hookah smoking, respectively. Current results underscore the importance of social well-being aspects in designing tobacco control interventions and show that promoting various dimensions of social wellbeing according to gender differences should not be neglected to achieve the desired result.

\section{List Of Abbreviations}

\section{TLGS}

Tehran Lipid and Glucose Study

DALYs

Disability-Adjusted Life Years

MAQ

Modifiable activity questionnaire

MET

Metabolic equivalent task

DM

Diabetes mellitus

CKD

Chronic kidney disease

CVD

Cardiovascular disease 
OR

Odds Ratio

$\mathrm{Cl}$

Confidence interval

\section{Declarations}

\section{Acknowledgements}

The authors would like to express their appreciation to all participants who made this study possible.

\section{Ethics approval and consent to participate}

The study was approved by the Ethical Committee of Research Institute for Endocrine Sciences and the National Research Council of the Islamic Republic of Iran (no. EC 121). Informed consent was obtained from all individual participants included in the study.

\section{Consent for publication}

In accordance with the ethical approvals mentioned all participants consented for their data to be included in the published manuscript.

\section{Availability of data and materials}

The datasets used and/or analyzed during the current study are available from the corresponding author on reasonable request.

\section{Competing interests}

The authors declare that they have no competing interests.

\section{Funding}

The authors received no financial support for the research, authorship, and/or publication of this article.

\section{Authors' contribution}

P A, H M-A, F M designed the study. LC carried out the statistical analysis. P A, H M-A, F M, H E-Z contributed to interpretation of data. HM-A, F M and N M drafted the manuscript. FA, PA and $\mathrm{H}$ E-Z supervised and revised the manuscript. All authors read and approved the final manuscript.

\section{References}

1. WHO Report on the Global Tobacco Epidemic GWHOL. IGO. CB-N-S. 2019.

2. Reitsma MB, Fullman N, Ng M, Salama JS, Abajobir A, Abate KH, et al. Smoking prevalence and attributable disease burden in 195 countries and territories, 1990-2015: a systematic analysis from the Global Burden of Disease Study 2015. The Lancet. 2017;389(10082):1885-906.

3. Varmaghani M, Sharifi F, Mehdipour P, Sheidaei A, Djalalinia S, Gohari K, et al. Prevalence of smoking among Iranian adults: findings of the national STEPs survey 2016. Arch Iran Med. 2020;23(6):369-77.

4. Meysamie A, Ghalehtaki R, Ghodsi S, Esteghamati A, Mohammad K, Etemad K, et al. Trend of cigarette smoking in Iranian adult population from 2000 to 2011 based on four national surveys. Social Determinants of Health. 2017;3(3):148-59.

5. Lawrence D, Mitrou F, Zubrick SR. Smoking and mental illness: results from population surveys in Australia and the United States. BMC Public Health. 2009;9(1):1-14.

6. Gurillo P, Jauhar S, Murray RM, MacCabe JH. Does tobacco use cause psychosis? Systematic review and meta-analysis. Lancet Psychiatry. 2015;2(8):718-25.

7. Waziry R, Jawad M, Ballout RA, Al Akel M, Akl EA. The effects of waterpipe tobacco smoking on health outcomes: an updated systematic review and meta-analysis. Int J Epidemiol. 2017;46(1):32-43.

8. Leonardi F. The definition of health: towards new perspectives. Int J Health Serv. 2018;48(4):735-48.

9. Gallagher MW, Lopez SJ, Preacher KJ. The hierarchical structure of well-being. Journal of personality. 2009;77(4):1025-50.

10. Flügel JC. A quantitative study of feeling and emotion in everyday life. Br J Psychol. 1925;15(4):318.

11. Ryff CD, Keyes CLM. The structure of psychological well-being revisited. J Personal Soc Psychol. 1995;69(4):719.

12. Keyes CLM. Social well-being. Social psychology quarterly. 1998:121 - 40.

13. Saito J, Shibanuma A, Yasuoka J, Kondo N, Takagi D, Jimba M. Education and indoor smoking among parents who smoke: the mediating role of perceived social norms of smoking. BMC Public Health. 2018;18(1):1-12.

Page $8 / 10$ 
14. Algren MH, Ekholm O, Nielsen L, Ersbøll AK, Bak CK, Andersen PT. Social isolation, loneliness, socioeconomic status, and health-risk behaviour in deprived neighbourhoods in Denmark: A cross-sectional study. SSM-population health. 2020;10:100546.

15. Glenn NM, Lapalme J, McCready G, Frohlich KL. Young adults' experiences of neighbourhood smoking-related norms and practices: a qualitative study exploring place-based social inequalities in smoking. Soc Sci Med. 2017;189:17-24.

16. Lakon CM, Valente TW. Social integration in friendship networks: The synergy of network structure and peer influence in relation to cigarette smoking among high risk adolescents. Soc Sci Med. 2012;74(9):1407-17.

17. De Walque D. Does education affect smoking behaviors?: Evidence using the Vietnam draft as an instrument for college education. J Health Econ. 2007;26(5):877-95.

18. Zeiher J, Kuntz B, Lange C. Smoking among adults in Germany. 2017.

19. Wang Q, Shen JJ, Sotero M, Li CA, Hou Z. Income, occupation and education: Are they related to smoking behaviors in China? PloS one. 2018;13(2):e0192571.

20. Montgomery SM, Cook DG, Bartley MJ, Wadsworth ME. Unemployment, cigarette smoking, alcohol consumption and body weight in young British men. The European Journal of Public Health. 1998;8(1):21-7.

21. Novo M, Hammarström A, Janlert U. Smoking habits-a question of trend or unemployment? A comparison of young men and women between boom and recession. Public Health. 2000;114(6):460-3.

22. Sreeramareddy CT, Harper S, Ernstsen L. Educational and wealth inequalities in tobacco use among men and women in 54 low-income and middle-income countries. Tobacco control. 2018;27(1):26-34.

23. Casetta B, Videla AJ, Bardach A, Morello P, Soto N, Lee K, et al. Association between cigarette smoking prevalence and income level: a systematic review and meta-analysis. Nicotine Tob Res. 2017;19(12):1401-7.

24. Gorini G, Carreras G, Allara E, Faggiano F. Decennial trends of social differences in smoking habits in Italy: a 30-year update. Cancer Causes Control. 2013;24(7):1385-91.

25. Tsai Y-W, Tsai T-I, Yang C-L, Kuo KN. Gender differences in smoking behaviors in an Asian population. Journal of Women's Health. 2008;17(6):971-8.

26. Jamil H, Templin T, Fakhouri M, Rice V, Khouri R, Fakhouri H, et al. Comparison of personal characteristics, tobacco use, and health states in Chaldean, Arab American, and non-Middle Eastern White adults. Journal of immigrant minority health. 2009;11(4):310-7.

27. Jamil H, Geeso SG, Arnetz BB, Arnetz JE. Risk factors for hookah smoking among arabs and chaldeans. Journal of immigrant minority health. 2014;16(3):501-7.

28. Afifi R, Khalil J, Fouad F, Hammal F, Jarallah Y, Farhat HA, et al. Social norms and attitudes linked to waterpipe use in the Eastern Mediterranean Region. Soc Sci Med. 2013;98:125-34.

29. Dadipoor S, Kok G, Aghamolaei T, Heyrani A, Ghaffari M, Ghanbarnezhad A. Factors associated with hookah smoking among women: a systematic review. Tobacco prevention \& cessation. 2019;5.

30. Delshad M, Ghanbarian A, Ghaleh NR, Amirshekari G, Askari S, Azizi F. Reliability and validity of the modifiable activity questionnaire for an Iranian urban adolescent population. International journal of preventive medicine. 2015;6.

31. Shayeghian Z, Amiri P, VAHEDI-NOTASH G, Karimi M, Azizi F. Validity and Reliability of the Iranian Version of the Short Form Social Well Being Scale in a General Urban Population. Iranian Journal of Public Health. 2019;48(8):1478.

32. Yun EH, Kang YH, Lim MK, Oh J-K, Son JM. The role of social support and social networks in smoking behavior among middle and older aged people in rural areas of South Korea: A cross-sectional study. BMC Public Health. 2010;10(1):78.

33. Ruhil R. Sociodemographic determinants of tobacco use in India: Risks of risk factor-An analysis of global adult tobacco survey India 20162017. SAGE Open. 2019;9(2):2158244019842447.

34. Gilani SI, Leon DA. Prevalence and sociodemographic determinants of tobacco use among adults in Pakistan: findings of a nationwide survey conducted in 2012. Population Health Metrics. 2013;11(1):16.

35. Palipudi K, Rizwan SA, Sinha DN, Andes LJ, Amarchand R, Krishnan A, et al. Prevalence and sociodemographic determinants of tobacco use in four countries of the World Health Organization: South-East Asia region: findings from the Global Adult Tobacco Survey. Indian J Cancer. 2014;51(Suppl 1):24-32.

36. Masho SW, Do E, Adekoya S. Social Support and Smoking during Pregnancy. J Womens Health Care. 2014;3:1000179.

37. Väänänen A, Kouvonen A, Kivimäki M, Pentti J, Vahtera J. Social support, network heterogeneity, and smoking behavior in women: the 10-town study. Am J Health Promot. 2008;22(4):246-55.

38. Maziak W, Rastam S, Eissenberg T, Asfar T, Hammal F, Bachir ME, et al. Gender and smoking status-based analysis of views regarding waterpipe and cigarette smoking in Aleppo, Syria. Prev Med. 2004;38(4):479-84.

39. Lee JJ, Yeung KCY, Wang MP, Thorne S. Arabian nights in Hong Kong: Chinese young adults' experience of waterpipe smoking. Tob Control. 2020. 
40. SOHRABZADEH M, PARNIAN L. Qualitative studies smoking hookah among girls and young women (case study: Shiraz City). 2015.

41. Dar-Odeh NS, Abu-Hammad OA. The changing trends in tobacco smoking for young Arab women; narghile, an old habit with a liberal attitude. Harm Reduction Journal. 2011;8(1):1-4.

Figures

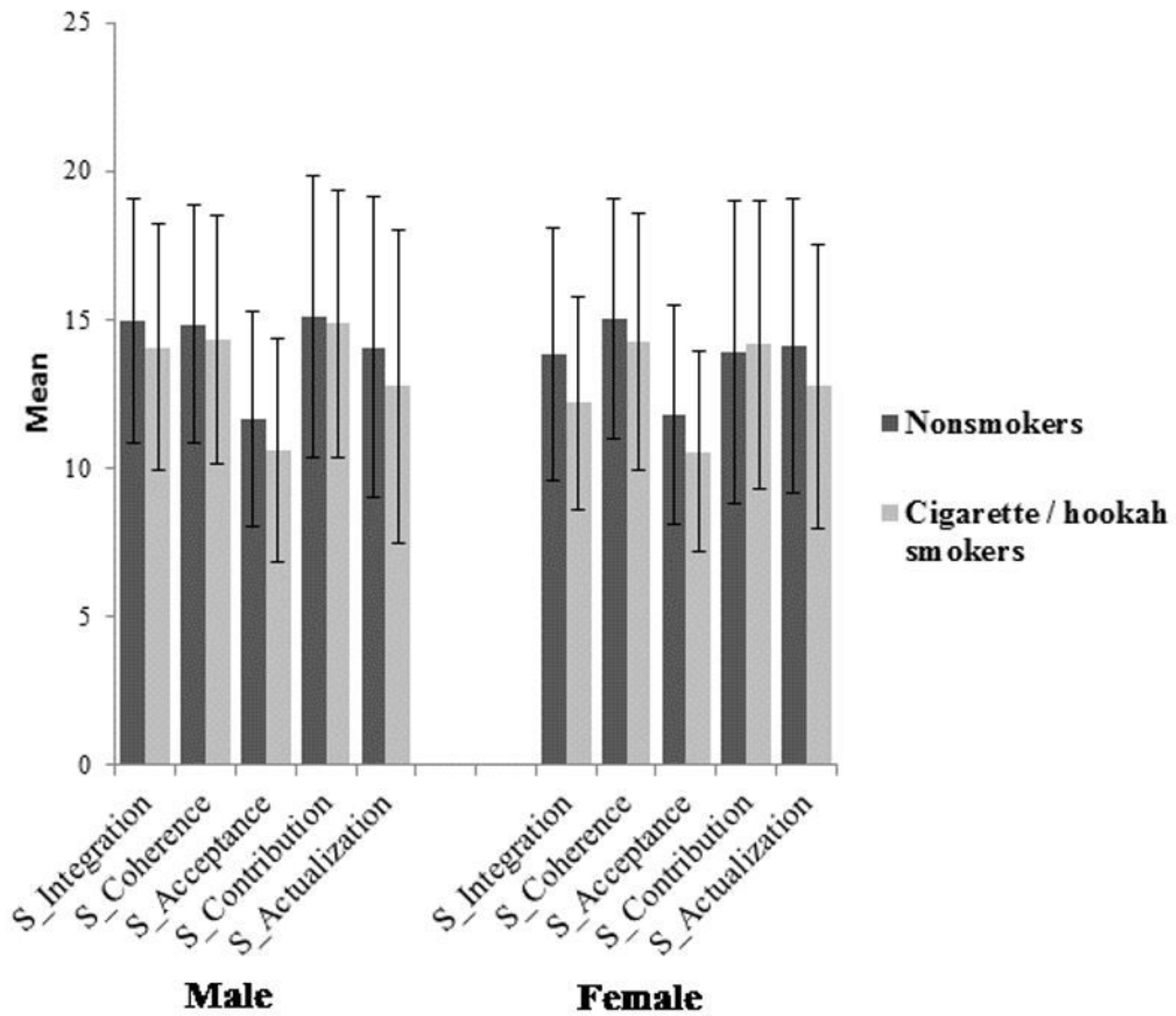

Figure 1

Scores of social well-being dimensions (mean and confidence intervals) in non-smoker and smokers (cigarette and hookah smokers) men and women. S-integration: Social integration, S-acceptance: Social acceptance, S- coherence: Social coherence, S- contribution: Social contribution, and S-actualization: Social actualization. 